\title{
The effect of discharge destination and primary insurance provider on hospital discharge delays among patients with traumatic brain injury: a multicenter study of 1,543 patients
}

Melissa Sorensen ${ }^{1}$, Erica Sercy ${ }^{2,3,4,5}$, Kristin Salottolo ${ }^{2,3,4,5}$, Michael Waxman ${ }^{6}$, Thomas A. West ${ }^{7}$, Allen Tanner $\|^{8}$ and David Bar-Or $2,3,4,5,9^{*}$

\begin{abstract}
Background: Hospital length of stay (HLOS) is a commonly used measure of hospital quality and is influenced by clinical and non-clinical factors. To reduce HLOS, it is key to identify factors placing patients at increased risk of lengthy HLOS and discharge delays.

Methods: This was a retrospective cohort study of patients age $\geq 18$ admitted to four level 1 trauma centers between 1/1/2015 and 3/31/2018 with traumatic brain injury (TBI). The primary outcome was discharge delay, defined as discharge $\geq 24 \mathrm{~h}$ after case management notes indicated the patient was ready for discharge. The independent variables of interest were primary insurance provider and discharge destination. Chi-square, Fisher exact, and unadjusted and adjusted logistic regression analyses were used to assess associations between discharge delay and the two primary independent variables, as well as other patient demographic and clinical characteristics. Complications developing during the delay period were also examined.

Results: A total of 1543 patients with TBI were included. The median age was 61 years, and the median HLOS was 5 days. Approximately half of patients were discharged home (54\%). The most common insurance providers were Medicare (35\%) and commercial/private (35\%). Two-hundred ten (14\%) patients experienced a discharge delay. The median delay period was 3 days, and the most common reasons for delay were insurance authorization (52\%) and lack of accepting bed (41\%). Compared to being discharged home, patients discharged to a skilled nursing facility (adjusted odds ratio $(A O R)=10.35$ ) or intermediate care facility $(A O R=10.64)$ had the highest odds of discharge delay. Compared to Medicare patients, uninsured/self-pay patients $(A O R=2.98)$ and those with Medicaid $(A O R=$ 2.83) or commercial/private insurance $(A O R=2.22)$ had higher odds of delay. Thirty-two patients ( $15 \%$ of those delayed) experienced at least one complication during the delay, some of which were clinically severe.
\end{abstract}

Conclusions: A substantial portion of TBI patients in this study experienced discharge delays, and discharge destination and primary insurance provider were significant drivers of these delays. Evaluation of a facility's quality of care should consider the specific causes of these delays.

Keywords: Patient discharge, Traumatic brain injury, Insurance

\footnotetext{
* Correspondence: davidbme49@gmail.com

${ }^{2}$ Trauma Research Department, Swedish Medical Center, Englewood, CO,

USA

${ }^{3}$ Trauma Research Department, Medical City Plano, Plano, TX, USA

Full list of author information is available at the end of the article
}

(c) The Author(s). 2020 Open Access This article is distributed under the terms of the Creative Commons Attribution 4.0 International License (http://creativecommons.org/licenses/by/4.0/), which permits unrestricted use, distribution, and reproduction in any medium, provided you give appropriate credit to the original author(s) and the source, provide a link to the Creative Commons license, and indicate if changes were made. The Creative Commons Public Domain Dedication waiver (http://creativecommons.org/publicdomain/zero/1.0/) applies to the data made available in this article, unless otherwise stated. 


\section{Background}

Among the many measures regularly used to assess hospital quality of care is hospital length of stay (HLOS). Hospital length of stay is used in this way by multiple evaluation organizations, including the Trauma Quality Improvement Program [1] and the Agency for Healthcare Research and Quality Healthcare Cost and Utilization Project $[2,3]$. Shorter average HLOS is often an important target of quality-improvement measures because of the association between longer HLOS and development of patient complications, [4-6] including mortality and hospitalacquired infection, as well as increased cost to the hospital, [7]. A key first step in intervening on this issue is identifying factors that place patients at increased risk for lengthy HLOS and delays in hospital discharge.

Multiple factors, both clinical and non-clinical, influence HLOS and discharge delays. Among patients with traumatic injury, previous studies have shown an association between higher injury severity and longer HLOS $[8,9]$. It has been suggested that non-clinical factors may also have a major role in HLOS among trauma patients [10-12]. One previous study found that clinical factors accounted for only $\sim 20 \%$ of hospital discharge delays at their facility over a 5 -year period, with the remainder of delays being due to in-hospital procedural delays, insurance-related issues, and placement to rehabilitation facilities at discharge [10]. Other studies using data from level 1 trauma centers and the National Trauma Data Bank found that the strongest predictor of lengthy HLOS was discharge destination [7, 12]. These previous findings point to HLOS being determined by factors that are both under a facility's control to intervene upon (e.g., hospital operational delays) and those that are not (e.g., patient clinical characteristics, discharge destination availability).

Patients with TBI, especially those with moderate or severe TBI, are at increased risk of lengthy HLOS because of their risk of intracranial hemorrhage, neurological deficits following injury, and potential need for neurosurgical procedures [13, 14]. According to the most recently available Centers for Disease Control and Prevention data, there were $\sim 2.87$ million TBI-related emergency room visits, hospitalizations, and deaths in 2014, [15] and this group comprises a substantial portion of all trauma patients in the United States. This patient population represents a large group that could be targeted in efforts to reduce HLOS in an individual facility or across a hospital system if modifiable factors can be identified that lead to increased HLOS among TBI patients.

The aim of this study was to focus on a specific group of trauma patients, those with TBI, and examine what clinical and non-clinical factors are associated with increased HLOS attributable to discharge delays. Although anecdotal evidence has suggested that discharge delays and delay-period complications are a significant issue among TBI patients at the level 1 trauma centers included in this study, the goals here were to quantify the scale of the issue and examine what factors-demographic, clinical, or administrative-place TBI patients at the highest risk of experiencing discharge delay, potentially offering targets for future interventions.

\section{Methods}

This was a retrospective cohort study on consecutively admitted trauma patients age 18 and older admitted to one of four level 1 trauma centers across three states between $1 / 1 / 2015$ and $3 / 31 / 2018$. This study was approved by the Institutional Review Board at each participating center and was granted a waiver of informed consent and HIPAA authorization. Patients were included if they were admitted to one of the participating centers with an ICD-9 or ICD-10 diagnosis code indicating TBI and an Injury Severity Score (ISS) $\geq 9$. Patients were excluded if they had an ICD-9 or ICD-10 diagnosis of a concussion only and had an Abbreviated Injury Scale (AIS) score $>2$ in any body region other than the head. These exclusion criteria aimed to focus on TBI more severe than concussion and increase the probability of the TBI being the primary injury. Patients were evaluated for inclusion and exclusion criteria using the trauma registries at each participating facility. Additional detailed patient information, including case management notes, reasons for discharge delay, insurance utilized, and complications experienced during the discharge delay period, were obtained via abstraction from patient electronic medical records.

Demographic and clinical characteristics collected on patients were age, sex, race, and the following comorbidities: history of substance abuse, presence of an advance healthcare directive, bleeding disorder or current anticoagulant use, cardiovascular disorder (congestive heart failure, hypertension, myocardial infarction, peripheral artery disease, coronary artery disease), cirrhosis of the liver, respiratory conditions (asthma, chronic obstructive pulmonary disease), history of stroke, dementia, functionally dependent health status, major psychiatric disorder, and current smoking. Injury and clinical characteristics included admission ISS, admission Glasgow Coma Scale (GCS) score, total HLOS, intensive care unit (ICU) LOS, mechanism of injury (fall, motor vehicle collision, assault, other), discharge disposition (home/home health, rehabilitation facility, skilled nursing facility (SNF), hospice, intermediate care facility (ICF), longterm acute care (LTAC)/nursing home, other, death), and undergoing a neurosurgical intervention (craniotomy, craniectomy, craniostomy, burr hole, surgical elevation of skull fracture, placement of intracranial pressure monitor, ventriculostomy) during hospital stay. Administrative details 
collected were primary insurance provider (commercial/private, Medicare, Medicaid, Military, uninsured/self-pay, other), utilization of secondary insurance, and secondary insurance provider.

The primary outcome was experiencing a discharge delay, defined here as discharge $\geq 24 \mathrm{~h}$ after case management notes indicated the patient was medically ready for discharge. The primary independent variables of interest were discharge disposition and primary insurance provider; however, all demographic, clinical, and administrative factors were also examined for associations with discharge delay. Chi-square or Fisher exact tests were used to examine differences in demographic, clinical, and administrative characteristics between patients who experienced delay and those who did not. Unadjusted and adjusted logistic regression analyses were used to further investigate associations between demographic, clinical, and administrative characteristics and experiencing a discharge delay. In the adjusted model, the two independent variables of interest, discharge disposition and primary insurance provider, and all variables that showed significance in unadjusted models were made available for inclusion in the final model. Stepwise selection with entry and exit criteria of $\alpha=0.05$ was used to determine the variables remaining in the final adjusted model.

Further analyses were used to describe the discharge delay periods in more detail. The median days between admission and start of delay and the median total delay days were calculated, and the reasons for the discharge delays were described. In addition, complications that developed during the discharge delay period were collected, as well as the median hours between the beginning of the delay period and development of the first post-delay complication. All statistical analyses were conducted in SAS version 9.4.

\section{Results}

This study included a total of 1543 patients with TBI admitted to the four participating centers over the study period. The median age of the patient population was 61 years, $60 \%$ were male, and the majority were white (79\%) (Table 1). The most common comorbidities were a cardiovascular condition (45\%), current smoking (20\%), substance abuse (17\%), and diabetes (15\%). The most common cause of injury was a fall (60\%), followed by a motor vehicle collision (20\%). The median ISS was 14 , and the median GCS score was 15 , indicating only minor cognitive impairment among most of the patient population. The median HLOS was 5 days, and the median ICU LOS among those patients with ICU stays was 2 days. One-hundred eighty-six patients (12\%) had a neurosurgical intervention during their hospital stay.
The most common discharge destination was home or home health (54\%), followed by a rehabilitation facility $(18 \%)$, and a SNF (10\%). The most commonly utilized primary insurance providers were Medicare $(35 \%)$ and commercial/private insurance (35\%). Two-hundred seven patients (13\%) utilized a secondary form of insurance, and the most common secondary insurance provider was commercial/private insurance ( $34 \%$ of those using a secondary insurance provider).

Of the 1543 total TBI patients, 210 (14\%) experienced a discharge delay. The median time between admission and delay start was 6 days, and the median delay period was 3 days, meaning that patients remained in the hospital for approximately 3 days after case management notes indicated they ready for discharge (Table 1). The most common reason for the delay was insurance processing or authorization (52\% of patients with delay), followed by lack of an accepting bed at the receiving facility (41\% of patients with delay) and patient-related reasons (e.g., language barrier, coordination with family members; $34 \%$ of all delayed patients). Total HLOS and ICU LOS were both significantly longer in delayed patients (HLOS: 10 days vs 4 days for non-delayed patients, $P<0.01$; ICU LOS: 5 days vs 2 days, $P<0.01$ ).

Clinical factors univariately associated with delay included presence of a psychiatric comorbidity (16\% vs $7 \%$ of non-delayed patients, $P<0.01)$ and cirrhosis of the liver ( $3 \%$ vs $1 \%, P=0.02$ ) (Table 1 ), a higher median ISS (17 vs $14, P<0.01)$ and motor vehicle collision as the injury cause $(28 \%$ vs $19 \%, P<0.01)$. The median (IQR) GCS score for delayed patients was $14(8-15)$ compared to 15 (14-15) for non-delayed patients $(P<0.01)$, indicating that delayed patients had a larger range of GCS scores and were more likely to have cognitive impairment than nondelayed patients. Delayed patients were more likely to have undergone a neurosurgical intervention during their hospital stay $(19 \%$ vs $11 \%, P<0.01)$. Of the total delayed patients who underwent neurosurgical intervention $(n=$ 40), 35 of these patients (88\%) had the neurosurgical intervention prior to the start of the delay. Administrative factors univariately associated with delay were hospital discharge to a facility other than home $(P<0.01)$ and utilization of a secondary form of insurance (19\% vs $13 \%$, $P<0.01)$. Primary insurance status was not associated with discharge delay prior to adjustment.

In adjusted logistic regression analyses, both clinical and administrative features were significantly associated with experiencing discharge delay (Table 2). Both discharge destination and primary insurance provider were significantly associated with discharge delay. Patients discharged to a SNF (OR $=10.35,95 \%$ CI 6.06-17.96) or ICF $(\mathrm{OR}=10.64,95 \%$ CI 5.27-21.46) were the most likely to have a delay compared to those discharged home. Patients utilizing commercial/private insurance 
Table 1 Differences in clinical and administrative factors in patients with and without discharge delays

\begin{tabular}{|c|c|c|c|c|}
\hline & $\begin{array}{l}\text { Overall study population } \\
n=1543\end{array}$ & $\begin{array}{l}\text { Delayed } \\
n=210(13.6 \%)\end{array}$ & $\begin{array}{l}\text { Not Delayed } \\
n=1333(86.4 \%)\end{array}$ & $P$ \\
\hline \multicolumn{5}{|l|}{ Delay Details } \\
\hline Days from admission to delay start, median (IQR), range & - & $6(3-12)$ & - & \\
\hline Delay days, median (IQR) & - & $3(2-6)$ & - & \\
\hline \multicolumn{5}{|l|}{ Reason for delay } \\
\hline Insurance & - & 109 (51.9\%) & - & \\
\hline Accepting bed & - & $85(40.5 \%)$ & - & \\
\hline Patient & - & $72(34.3 \%)$ & - & \\
\hline Provider & - & $12(5.7 \%)$ & - & \\
\hline Procedure & - & $9(4.3 \%)$ & - & \\
\hline Test & - & $9(4.3 \%)$ & - & \\
\hline HLOS days, median (IQR) & $5(3-9)$ & $10(7-19)$ & $4(2-7)$ & $<0.01$ \\
\hline ICU LOS days, median (IQR) & $2(1-5)$ & $5(3-10)$ & $2(1-4)$ & $<0.01$ \\
\hline \multicolumn{5}{|l|}{ Patient Demographics } \\
\hline Age, median (IQR) & $61(40-78)$ & $63(46-79)$ & $61(39-77)$ & 0.27 \\
\hline Sex & & & & 0.61 \\
\hline Male & $923(59.8 \%)$ & $129(61.4 \%)$ & $794(59.6 \%)$ & \\
\hline Female & $620(40.2 \%)$ & $81(38.6 \%)$ & $539(40.4 \%)$ & \\
\hline Race & & & & 0.64 \\
\hline White & 1187 (78.9\%) & $164(81.6 \%)$ & $1023(78.5 \%)$ & \\
\hline Black & $151(10.0 \%)$ & $20(10.0 \%)$ & $131(10.1 \%)$ & \\
\hline Hispanic & $23(1.5 \%)$ & $2(1.0 \%)$ & $21(1.6 \%)$ & \\
\hline Other & $143(9.5 \%)$ & $15(7.5 \%)$ & $128(9.8 \%)$ & \\
\hline \multicolumn{5}{|l|}{ Clinical Characteristics } \\
\hline ISS, median (IQR) & $14(10-21)$ & $17(11-25)$ & $14(10-20)$ & $<0.01$ \\
\hline GCS, median (IQR) & $15(14-15)$ & $14(8-15)$ & $15(14-15)$ & $<0.01$ \\
\hline \multicolumn{5}{|l|}{ Comorbidities } \\
\hline Cardiovascular & $692(44.9 \%)$ & $98(46.7 \%)$ & $594(44.6 \%)$ & 0.57 \\
\hline Smoker & 309 (20.0\%) & $38(18.1 \%)$ & $271(20.3 \%)$ & 0.45 \\
\hline Substance abuse & $263(17.0 \%)$ & $41(19.5 \%)$ & $222(16.7 \%)$ & 0.30 \\
\hline Diabetes & $236(15.3 \%)$ & $34(16.2 \%)$ & $202(15.2 \%)$ & 0.70 \\
\hline Bleeding disorder & $166(10.8 \%)$ & $22(10.5 \%)$ & $144(10.8 \%)$ & 0.89 \\
\hline Dementia & 137 (8.9\%) & $23(11.0 \%)$ & $114(8.6 \%)$ & 0.26 \\
\hline Psychiatric & $121(7.8 \%)$ & $33(15.7 \%)$ & $88(6.6 \%)$ & $<0.01$ \\
\hline Respiratory & $108(7.0 \%)$ & $18(8.6 \%)$ & $90(6.8 \%)$ & 0.34 \\
\hline Previous stroke & $103(6.7 \%)$ & $17(8.1 \%)$ & $86(6.5 \%)$ & 0.38 \\
\hline Functionally dependent health status & $101(6.6 \%)$ & $12(5.7 \%)$ & $89(6.7 \%)$ & 0.60 \\
\hline Advanced directive & $51(3.3 \%)$ & $9(4.3 \%)$ & $42(3.2 \%)$ & 0.39 \\
\hline Cirrhosis & $22(1.4 \%)$ & 7 (3.3\%) & $15(1.1 \%)$ & 0.02 \\
\hline Mechanism of injury & & & & 0.01 \\
\hline Fall & $924(59.9 \%)$ & $117(55.7 \%)$ & $807(60.5 \%)$ & \\
\hline Motor vehicle collision & $306(19.8 \%)$ & $59(28.1 \%)$ & $247(18.5 \%)$ & \\
\hline Assault & $87(5.6 \%)$ & $9(4.3 \%)$ & $78(5.9 \%)$ & \\
\hline Other & $226(14.7 \%)$ & $25(11.9 \%)$ & $201(15.1 \%)$ & \\
\hline
\end{tabular}


Table 1 Differences in clinical and administrative factors in patients with and without discharge delays (Continued)

\begin{tabular}{|c|c|c|c|c|}
\hline & Overall study population & Delayed & Not Delayed & $P$ \\
\hline & $n=1543$ & $n=210(13.6 \%)$ & $n=1333(86.4 \%)$ & \\
\hline Neurosurgical intervention & $186(12.1 \%)$ & $40(19.1 \%)$ & $146(11.0 \%)$ & $<0.01$ \\
\hline Neurosurgical intervention prior to delay & - & $35(16.7 \%)$ & - & - \\
\hline \multicolumn{5}{|l|}{ Administrative } \\
\hline Discharge disposition & & & & $<0.01$ \\
\hline Home/home health & $826(53.5 \%)$ & $43(20.5 \%)$ & $783(58.7 \%)$ & \\
\hline Rehabilitation facility & $284(18.4 \%)$ & $78(37.1 \%)$ & $206(15.5 \%)$ & \\
\hline Skilled nursing facility & $157(10.2 \%)$ & $44(21.0 \%)$ & $113(8.5 \%)$ & \\
\hline Hospice & $78(5.1 \%)$ & $5(2.4 \%)$ & $73(5.5 \%)$ & \\
\hline Intermediate care facility & $68(4.4 \%)$ & $18(8.6 \%)$ & $50(3.8 \%)$ & \\
\hline Long-term acute care/nursing home & $51(3.3 \%)$ & $14(6.7 \%)$ & $37(2.8 \%)$ & \\
\hline Other & $46(3.0 \%)$ & $4(1.9 \%)$ & $44(3.3 \%)$ & \\
\hline Death & $31(2.0 \%)$ & $4(1.9 \%)$ & $27(2.0 \%)$ & \\
\hline Primary insurance & & & & 0.32 \\
\hline Medicare & $539(35.0 \%)$ & $62(29.7 \%)$ & 477 (35.9\%) & \\
\hline Commercial/private & $534(34.7 \%)$ & $81(38.8 \%)$ & $453(34.1 \%)$ & \\
\hline Uninsured/self-pay & $204(13.3 \%)$ & $28(13.4 \%)$ & $176(13.2 \%)$ & \\
\hline Medicaid & $148(9.6 \%)$ & $25(12.0 \%)$ & $123(9.3 \%)$ & \\
\hline Other & $83(5.4 \%)$ & $11(5.3 \%)$ & $72(5.4 \%)$ & \\
\hline Military & $31(2.0 \%)$ & $2(1.0 \%)$ & $29(2.2 \%)$ & \\
\hline Secondary insurance utilized & $207(13.4 \%)$ & $40(19.1 \%)$ & $167(12.5 \%)$ & $<0.01$ \\
\hline Secondary insurance & & & & 0.43 \\
\hline Medicare & $47(22.7 \%)$ & $9(22.5 \%)$ & $38(22.8 \%)$ & \\
\hline Commercial/private & $70(33.8 \%)$ & $9(22.5 \%)$ & $61(36.5 \%)$ & \\
\hline Self-pay & $25(12.1 \%)$ & $5(12.5 \%)$ & $20(12.0 \%)$ & \\
\hline Medicaid & $33(15.9 \%)$ & $10(25.0 \%)$ & $23(13.8 \%)$ & \\
\hline Other & $19(9.2 \%)$ & $4(10.0 \%)$ & $15(9.0 \%)$ & \\
\hline Military & $13(6.3 \%)$ & $3(7.5 \%)$ & $10(6.0 \%)$ & \\
\hline
\end{tabular}

IQR interquartile range; HLOS hospital length of stay; LOS length of stay; ICU intensive care unit; ISS Injury Severity Score; GCS Glasgow Coma Scale. Bold indicates statistical significance at a threshold of $P<0.05$. Unless otherwise indicated, results are shown as $\mathrm{n}(\%)$

$(\mathrm{OR}=2.22,95 \%$ CI 1.46-3.38), Medicaid $(\mathrm{OR}=2.83$, 95\% CI 1.52-5.25), or another insurance type (OR= $2.32,95 \%$ CI 1.01-5.30) as their primary insurance provider and those who were self-pay or uninsured (OR = $2.98,95 \%$ CI $1.62-5.47$ ) were more likely to have a delay than those utilizing Medicare. Patients with cirrhosis $(\mathrm{OR}=3.93$, 95\% CI 1.39-11.13) and those with psychiatric comorbidities $(\mathrm{OR}=2.99,95 \%$ CI 1.80-4.96) were significantly more likely to experience discharge delay. In addition, a lower GCS score, indicating more severe cognitive impairment, was significantly associated with discharge delay $(\mathrm{OR}=0.95,95 \%$ CI 0.91-0.99).

Thirty-two patients (15\% of delayed patients) experienced at least one complication during their delay period, and 16 patients (8\%) experienced at least two complications (Table 3). The median time between the beginning of the delay period and development of the first complication was $71 \mathrm{~h}$. The most common complications were altered mental status (increasing anxiety or anxiety attack, delirium, increasing distress; 5\%), altered blood labs (hypoxia, anemia, hyponatremia, leukocytosis; $4 \%)$, and urinary tract infection (3\%). Among the most clinically severe complications during the delay period were development of a brain abscess $(n=1)$, enlarged brain ventricles $(n=1)$, deep vein thrombosis $(n=1)$, and new-onset intracranial hemorrhage $(n=1)$. Four patients ( $2 \%$ of delayed patients) died during their discharge delay period.

\section{Discussion}

Hospital length of stay is often used to assess the quality of care provided at a facility, as lengthy HLOS and discharge delays have been associated with in-hospital complications, patient mortality, and increased cost to the 
Table 2 Associations of clinical and administrative factors with experiencing discharge delay

\begin{tabular}{|c|c|c|}
\hline & Unadjusted & Adjusted \\
\hline & OR $(95 \% \mathrm{Cl})$ & OR $(95 \% \mathrm{Cl})$ \\
\hline \multicolumn{3}{|l|}{ Patient Demographics } \\
\hline Age & $1.00(0.99-1.01)$ & \\
\hline \multicolumn{3}{|l|}{ Sex } \\
\hline Male & Ref & \\
\hline Female & $0.93(0.69-1.25)$ & \\
\hline \multicolumn{3}{|l|}{ Race } \\
\hline White & Ref & \\
\hline Black & $0.95(0.58-1.57)$ & \\
\hline Hispanic & $0.59(0.14-2.56)$ & \\
\hline Other & $0.73(0.42-1.28)$ & \\
\hline \multicolumn{3}{|l|}{ Clinical Characteristics } \\
\hline ISS & $1.04(1.02-1.06)$ & \\
\hline GCS & $0.90(0.87-0.93)$ & $0.95(0.91-0.99)$ \\
\hline \multicolumn{3}{|l|}{ Comorbidities } \\
\hline Substance abuse & $1.21(0.84-1.76)$ & \\
\hline Advanced directive & $1.38(0.66-2.87)$ & \\
\hline Bleeding disorder & $0.97(0.60-1.55)$ & \\
\hline Cardiovascular & $1.09(0.81-1.46)$ & \\
\hline Cirrhosis & $3.03(1.22-7.52)$ & $3.93(1.39-11.13)$ \\
\hline Respiratory & $1.30(0.76-2.20)$ & \\
\hline Previous stroke & $1.28(0.74-2.20)$ & \\
\hline Dementia & $1.32(0.82-2.11)$ & \\
\hline Functionally dependent health status & $0.85(0.46-1.58)$ & \\
\hline Diabetes & $1.08(0.73-1.61)$ & \\
\hline Psychiatric & $2.64(1.72-4.06)$ & $2.99(1.80-4.96)$ \\
\hline Smoker & $0.87(0.60-1.26)$ & \\
\hline \multicolumn{3}{|l|}{ Mechanism of injury } \\
\hline Fall & Ref & \\
\hline Motor vehicle collision & $1.65(1.17-2.32)$ & \\
\hline Assault & $0.80(0.39-1.63)$ & \\
\hline Other & $0.86(0.54-1.36)$ & \\
\hline \multicolumn{3}{|l|}{ Discharge disposition } \\
\hline Home/home health & Ref & Ref \\
\hline Rehabilitation facility & $6.90(4.61-10.31)$ & $8.12(5.12-12.89)$ \\
\hline Skilled nursing facility & $7.09(4.46-11.28)$ & $10.35(6.06-17.96)$ \\
\hline Hospice & $1.25(0.48-3.25)$ & $0.82(0.23-2.91)$ \\
\hline Intermediate care facility & $6.56(3.53-12.19)$ & $10.64(5.27-21.46)$ \\
\hline Long-term acute care/nursing home & $6.89(3.47-13.70)$ & $6.16(2.77-13.70)$ \\
\hline Other & $1.66(0.57-4.82)$ & $1.23(0.41-3.72)$ \\
\hline Death & $2.70(0.90-8.06)$ & $2.24(0.68-7.31)$ \\
\hline Neurosurgical intervention prior to delay & $2.44(1.61-3.70)$ & $1.84(1.12-3.01)$ \\
\hline
\end{tabular}


Table 2 Associations of clinical and administrative factors with experiencing discharge delay (Continued)

\begin{tabular}{|c|c|c|}
\hline & Unadjusted & Adjusted \\
\hline & OR $(95 \% \mathrm{Cl})$ & OR $(95 \% \mathrm{Cl})$ \\
\hline \multicolumn{3}{|l|}{ Insurance } \\
\hline \multicolumn{3}{|l|}{ Primary insurance } \\
\hline Medicare & Ref & Ref \\
\hline Commercial/private & $1.38(0.97-1.96)$ & $2.22(1.46-3.38)$ \\
\hline Uninsured/self-pay & $1.22(0.76-1.98)$ & $2.98(1.62-5.47)$ \\
\hline Medicaid & $1.56(0.94-2.59)$ & $2.83(1.52-5.25)$ \\
\hline Other & $1.18(0.59-2.34)$ & $2.32(1.01-5.30)$ \\
\hline Military & $0.53(0.12-2.28)$ & $0.72(0.14-3.51)$ \\
\hline Secondary insurance utilized & $1.64(1.12-2.40)$ & \\
\hline \multicolumn{3}{|l|}{ Secondary insurance } \\
\hline Medicare & Ref & \\
\hline Commercial/private & $0.62(0.23-1.71)$ & \\
\hline Self-pay & $1.06(0.31-3.58)$ & \\
\hline Medicaid & $1.84(0.65-5.19)$ & \\
\hline Other & $1.13(0.30-4.22)$ & \\
\hline Military & $1.27(0.29-5.57)$ & \\
\hline
\end{tabular}

OR odds ratio; $95 \%$ CI 95\% confidence interval; ISS Injury Severity Score; GCS Glasgow Coma Scale. Ref indicates the reference group in the logistic models. Bold indicates statistical significance at a threshold of $P<0.05$

Table 3 Delay-period complications

\begin{tabular}{|c|c|}
\hline Complication Details & Total $n=210$ \\
\hline Experienced $\geq 1$ delay-period complication & $32(15.2 \%)$ \\
\hline Hours from delay start to delay-period complication, median (IQR) & $71(23-153)$ \\
\hline \multicolumn{2}{|l|}{ Complication during delay } \\
\hline Altered mental status ${ }^{a}$ & $11(5.2 \%)$ \\
\hline Altered blood labs ${ }^{b}$ & $8(3.8 \%)$ \\
\hline Urinary tract infection & $7(3.3 \%)$ \\
\hline Neurological complications ${ }^{c}$ & $4(1.9 \%)$ \\
\hline Lung complications $^{d}$ & $4(1.9 \%)$ \\
\hline Pneumonia & $3(1.4 \%)$ \\
\hline Rash/allergic reaction & $3(1.4 \%)$ \\
\hline Thrombocytosis & $3(1.4 \%)$ \\
\hline Superficial vein thrombosis ${ }^{e}$ & $2(1.0 \%)$ \\
\hline Deep vein thrombosis & $1(0.5 \%)$ \\
\hline New-onset intracranial hemorrhage & $1(0.5 \%)$ \\
\hline Death during delay period & $4(1.9 \%)$ \\
\hline \multicolumn{2}{|l|}{ Number of complications during delay } \\
\hline 0 & $178(84.8 \%)$ \\
\hline 1 & $16(7.6 \%)$ \\
\hline$\geq 2$ & 16 (7.6\%) \\
\hline
\end{tabular}

$I Q R$ interquartile range

${ }^{a}$ Altered mental status included increasing anxiety or anxiety attack, delirium, and increasing distress. ${ }^{\mathrm{b}}$ Altered blood labs included hypoxia, anemia, hyponatremia, and leukocytosis. 'Neurological complications included brain abscess, dysphasia, enlarged brain ventricles, and diplopia. ${ }^{\mathrm{d}}$ Lung complications included bilateral pleural effusions, atelectasis, retained left hemothorax, and bronchial herpes simplex type 1. ${ }^{~}$ Veins affected were the basilic vein and the cephalic vein. Unless otherwise indicated, results are shown as $\mathrm{n}(\%)$ 
hospital. This issue is especially pertinent among patients with TBI, as they comprise a substantial portion of the total trauma population and are already at increased risk for longer HLOS and complications because of the severity and nature of their injuries. This study found that among patients with TBI admitted to four level 1 trauma centers over $\sim 3$ years, a substantial portion (14\%) experienced delays in hospital discharge. The factors most strongly associated with experiencing delay were discharge destination, primary insurance provider, and certain patient comorbidities.

Previous studies have examined the reasons behind lengthy HLOS and discharge delays among trauma patients, with the aim of identifying areas for potential intervention and procedural change. Some of these reasons identified previously, such as hospital operational delays, [10] represent good targets for quality-improvement measures. Additionally, clinical factors associated with increased HLOS, such as injury severity $[8,9]$, lower GCS, and the presence of certain comorbidities, as found here, may help identify specific patient groups at higher risk for longer HLOS and discharge delays. However, consistent with previous studies that found discharge destination to be a major factor influencing HLOS, $[7,12]$ we found that two external administrative factors were the primary drivers of hospital discharge delays among TBI patients in our study: primary insurance provider and discharge destination.

Compared to patients discharged home, those being discharged to a SNF or ICF had the highest odds of experiencing discharge delay. Patients utilizing Medicare as their primary insurance provider had the lowest odds of delay, and patients utilizing commercial/private insurance or Medicaid and patients who were uninsured or self-pay had increasing odds of delay. Consistent with our findings, a previous study examining delays in placement to nursing homes found that utilizing Medicaid as a primary insurance provider was significantly associated with delays in discharge and placement [16]. Also in accordance with our results here, a previous study in stroke patients found that private/commercial insurance providers frequently require pre-certification before discharge to a SNF or inpatient rehabilitation facility, resulting in substantial discharge delays for patients with this type of primary insurance [17]. Our finding that the most common causes of delay were insurance processing and authorization and lack of available beds at the discharge destination, in conjunction with the findings of previous studies, imply that a complex network of approval and communication between insurance providers and discharge locations exists that has the potential to result in lengthy HLOS and discharge delays.

This study also found that among patients who experienced discharge delays, $15 \%$ had at least one complication develop during the delay period, consistent with previous studies linking increased HLOS with increased complications [4-6]. The most common complication here was altered mental status, although some of the less frequent complications were more clinically severe, such as brain abscess, enlarged brain ventricles, deep vein thrombosis, and new-onset intracranial hemorrhage. Importantly, four patients, or $2 \%$ of all delayed patients, died during their delay period. It is unknown whether the increased HLOS was the cause of many of these complications, which may have developed regardless of the patient's location. However, it is possible that complications such as pneumonia or urinary tract infection may plausibly be associated with a lengthy hospital stay.

A potential limitation of this study was an inability to capture the many detailed and varying insurance provider policies and practices that affect hospital discharge timeliness, in addition to those examined here. For example, this study did not consider the day of the week on which the patient was ready for discharge; discharge readiness on a Friday afternoon or prior to a holiday may result in discharge delays because of insurance company closure or personnel shortages. It may be worth parsing insurancerelated delays further than what was done here to enable specifically targeted interventions to eliminate such delays. It may additionally be useful to examine insurance reimbursement policies during delay periods, as well as what increased costs the insurance provider, hospital, and patient may incur during these delays.

An additional potential limitation of this study was the definition of discharge delay used: discharge $\geq 24 \mathrm{~h}$ after case management notes indicated the patient was ready. This may have been too stringent a cutoff, although it is likely that the appropriate definition of delay depends on typical practices at individual facilities. This study was also not able to assess the cause or directionality of the relationship between complications and discharge delays. We cannot say that longer HLOS caused the complications observed here, although we can report that a significant association existed among our patient population. In addition, it is likely that complications that developed during the delay period resulted in further additional delays, although we were not able to assess this here. The findings of this study are directly applicable to one subset of hospitalized patients only: those with TBI. Additionally, insurance reimbursement policies, availability of discharge destination beds, and other factors affecting discharge timeliness may differ by region, state, and rurality of the facility and may not directly reflect the conditions present at the facilities included here. However, despite these differences, it is likely that other groups of trauma patients experience similar issues with insurance and discharge destination delays. The large sample size and inclusion of four level 1 trauma centers across three states ensured that our study had sufficient power to examine differences 
in characteristics between delayed and non-delayed patients and conduct adjusted analyses to look for independent associations with the outcome.

\section{Conclusions}

It is worth exploring whether insurance processing delays and communication with the discharge destination can be intervened upon at the acute care hospital, prior to discharge. Perhaps hospital resources may be devoted to additional staff that facilitate smoother and more timely processing of discharge orders and insurance claims, acting as a mediator between insurance providers and discharge destinations. Although it appears that there may be no available action at the discharging hospital in response to a lack of available beds at the receiving facility, an awareness of the shortage, as well as the associated medical and financial consequences, at a systems or regional level may help shape facility planning on a larger scale. Lengthy HLOS and discharge delays are a multi-faceted issue, and it is worth considering the specific causes of these delays and what solutions may be implemented to address them when evaluating the quality of care at an individual facility.

\section{Abbreviations}

AIS: Abbreviated Injury Scale; AOR: Adjusted odds ratio; Cl: Confidence interval; GCS: Glasgow Coma Scale; HLOS: Hospital length of stay; ICF: Intermediate care facility; ICU: Intensive care unit; IQR: Interquartile range; ISS: Injury Severity Score; LOS: Length of stay; LTAC: Long-term acute care; OR: Odds ratio; SNF: Skilled nursing facility; TBI: Traumatic brain injury

\section{Acknowledgements}

We acknowledge the invaluable contributions of the clinical study coordinators at each participating center, without whom this study would not have been possible: Diane Redmond, MSN, RN, CCRP, CPHQ, at Penrose Hospital, Colorado Springs, CO; Kathy Rodkey, RCIS, CCRC, at Medical City Plano, Plano, TX; Shenequa Deas, MPH, COMR, CCRC, at Research Medical Center, Kansas City, MO; and Carolyn Blue, BSN, at Swedish Medical Center, Denver, CO.

\section{Authors' contributions}

MS conceived of the study, aided in study design, contributed vital data interpretation, added critical revisions to the manuscript, and reviewed the final version of the manuscript. ES performed the literature search, aided in study design and data collection, performed all data analyses, contributed to data interpretation, wrote the draft of the manuscript, contributed critical revisions to the manuscript, and reviewed the final version of the manuscript. KS aided in study design, contributed to data interpretation, contributed critical revisions to the manuscript, and reviewed the final version of the manuscript. TAW aided in study design, contributed to data interpretation, contributed critical revisions to the manuscript, and reviewed the final version of the manuscript. MW aided in study design, contributed to data interpretation, contributed critical revisions to the manuscript, and reviewed the final version of the manuscript. AT II aided in study design, contributed to data interpretation, contributed critical revisions to the manuscript, and reviewed the final version of the manuscript. DB-O oversaw the project, aided in study conception and design, contributed to data interpretation, contributed critical revisions to the manuscript, and reviewed the final version of the manuscript. All authors have read and approved the final manuscript.

\section{Funding}

Only internal funding was used for this study.

\section{Availability of data and materials}

The datasets generated and/or analyzed during the current study are not publicly available because they contain patient data but are available from the corresponding author on reasonable request.

\section{Ethics approval and consent to participate}

This study received expedited approval and waivers of HIPAA and informed consent from the Institutional Review Boards of each participating institution: HCA-HealthONE IRB, Denver, CO (reference number 1291495-3); Medical City Plano Institutional Review Board, Plano, TX (reference number 1290977-5); Catholic Health Initiatives Institute for Reach and Innovation Institutional Review Board (CHIRB), Englewood, CO (reference number 1291494-3); Western Institutional Review Board, Puyallup, WA (reference number 1246826).

\section{Consent for publication}

Not applicable.

\section{Competing interests}

The authors declare that they have no competing interests.

\section{Author details}

${ }^{1}$ Trauma Services Department, Swedish Medical Center, Englewood, CO, USA. ${ }^{2}$ Trauma Research Department, Swedish Medical Center, Englewood, CO, USA. ${ }^{3}$ Trauma Research Department, Medical City Plano, Plano, TX, USA. ${ }^{4}$ Trauma Research Department, Research Medical Center, Kansas City, MO, USA. ${ }^{5}$ Trauma Research Department, Penrose Hospital, Colorado Springs, CO, USA. ${ }^{6}$ Medical/Surgical Intensive Care Unit, Research Medical Center, Kansas City, MO, USA. 7 Trauma Services Department, Medical City Plano, Plano, TX, USA. ${ }^{8}$ Trauma Services Department, Penrose Hospital, Colorado Springs, CO, USA. ${ }^{9}$ Injury Outcomes Network Research Group, 501 E Hampden Ave, Englewood, CO 80113, USA.

Received: 15 November 2019 Accepted: 30 December 2019

Published online: 06 January 2020

\section{References}

1. American College of Surgeons. ACS Trauma Quality Improvement Program benchmark report: all patients, 2010 admissions. 2010. American College of Surgeons, Chicago, IL. http://web4.facs.org/tqipfiles/ACS TQIP Benchmark Report All Patients 2010 Admissions.pdf. Accessed 23 August 2019.

2. McDermott KW, Elixhauser A, Sun R. Trends in hospital inpatient stays in the United States, 2005-2014. HCUP Statistical Brief \#225. June 2017. Agency for Healthcare Research and Quality, Rockville, MD.

3. Agency for Healthcare Research and Quality. Examples of hospital quality measures for consumers. March2016. Agency for Healthcare Research and Quality, Rockville, MD. https://www.ahrq.gov/talkingquality/measures/ setting/hospitals/examples.html. Accessed 23 August 2019.

4. Ingeman A, Andersen G, Hundborg HH, Svendsen ML, Johnsen SP. Inhospital medical complications, length of stay, and mortality among stroke unit patients. Stroke. 2011;42:3214-8.

5. Mitchell BG, Ferguson JK, Anderson M, Sear J, Barnett A. Length of stay and mortality associated with healthcare-associated urinary tract infections: a multi-state model. J Hosp Infect. 2016:93:92-9.

6. Al-Tawfiq JA, Tambyah PA. Healthcare associated infections (HAI) perspectives. J Infect Public Health. 2014;7:339-44.

7. Thomas SN, McGwin G, Rue LW. The financial impact of delayed discharge at a level I trauma center. J Trauma Inj Infect Crit Care. 2005;58:121-5.

8. Newgard CD, Fleischman R, Choo E, John Ma O, Hedges JR, John MCK. Validation of length of hospital stay as a surrogate measure for injury severity and resource use among injury survivors. Acad Emerg Med. 2010; 17:142-50.

9. Salehi O, Tabibzadeh Dezfuli SA, Namazi SS, Dehghan Khalili M, Saeedi M. A new injury severity score for predicting the length of hospital stay in multiple trauma patients. Trauma Mon. 2016;21:e20349.

10. Hwabejire JO, Kaafarani HMA, Imam AM, Solis CV, Verge J, Sullivan NM, et al. Excessively long hospital stays after trauma are not related to the severity of illness. JAMA Surg. 2013;148:956.

11. Cryer C, Gulliver P, Langley JD, Davie G. Is length of stay in hospital a stable proxy for injury severity? Inj Prev. 2010;16:254-60.

12. Brasel KJ, Lim HJ, Nirula R, Weigelt JA. Length of stay. Arch Surg. 2007;142: 461. 
13. Boulanger L, Joshi AV, Tortella BJ, Menzin J, Caloyeras JP, Russell MW. Excess mortality, length of stay, and costs associated with serious hemorrhage among trauma patients: findings from the National Trauma Data Bank $k^{\oplus}$. Am Surg. 2007;73:1269-74.

14. High W, Hall K, Rosenthal M, Mann N, Zafonte R, Cifu D, et al. Factors affecting hospital length of stay and charges following traumatic brain injury. J Head Trauma Rehabil. 1996;11:85-96.

15. Centers for Disease Control and Prevention. Traumatic brain injury \& concussion. TBl: get the facts. https:/www.cdc.gov/traumaticbraininjury/ get_the_facts.html. Accessed 25 September 2019.

16. Weissert WG, Cready CM. Determinants of hospital-to-nursing home placement delays: a pilot study. Health Serv Res. 1988;23:619-47.

17. Smith AL, Kulhari A, Wolfram JA, Furlan A. Impact of insurance precertification on discharge of stroke patients to acute rehabilitation or skilled nursing facility. J Stroke Cerebrovasc Dis. 2017;26:711-6.

\section{Publisher's Note}

Springer Nature remains neutral with regard to jurisdictional claims in published maps and institutional affiliations.

Ready to submit your research? Choose BMC and benefit from:

- fast, convenient online submission

- thorough peer review by experienced researchers in your field

- rapid publication on acceptance

- support for research data, including large and complex data types

- gold Open Access which fosters wider collaboration and increased citations

- maximum visibility for your research: over $100 \mathrm{M}$ website views per year

At BMC, research is always in progress.

Learn more biomedcentral.com/submissions 